\title{
A PI control system to work PV cell at fixed temperature and under constant radiation
}

\author{
E. Kelebekler
}

\begin{abstract}
Electrical conversion efficiency of photovoltaic cells/modules/panels decreases with increase the temperature of PV cell/module/panel. A part of the incoming solar radiation is converted into useful electrical power by PV cells and the remaining is lost as waste heat. Furthermore, this waste heat causes to raise the cell temperature. When PV cell temperature rises, the open circuit voltage and fill factor decrease. In generally, mono-crystalline or poly-crystalline PV modules are used at experimental structures in alternative energy technology laboratories because output powers are higher and size is smaller. On the other hand, heat sensitiveness of crystalline silicon systems is higher than thin film technologies and their efficiency drops concretely while temperature rises. In laboratory conditions, the PV modules are usually illuminated with halogen lamps. The halogen lambs cause to warm rapidly PV modules. Consequently, accurate current-voltage characteristics of PV module for fixed illumination value usually cannot be determined because of increasing temperature during the experimental process. In the study, experimental investigation has been performed in order to detect cooling capability of direct air blow of prepared cooling system with two ventilators. Besides a control system with PI controller to work a 4.04W polycrystalline silicon PV cell at fixed working temperature and under constant solar radiation simulated with 500W halogen lamp has been constructed. Validation of the constructed system has been shown by using the experimental results and presented in figures.
\end{abstract}

Keywords - Data acquisition, heat behavior of PV cells, PI controller, polycrystalline silicon PV cell, PV working temperature, PWM.

\section{INTRODUCTION}

Photovoltaic (PV) cells which convert solar energy directly into electrical energy are renewable energy devices. Photovoltaic (PV) systems are safe, reliable and environmentally friendly source of energy. During the energy conversion process, $\mathrm{PV}$ cells only convert part of the incoming solar radiation into useful electrical power and the remaining is lost as waste heat. Additionally, the waste heat raises the cell temperature. When PV cell temperature increases, the open circuit voltage and fill factor is reduced, which decreases the conversion efficiency of the PV system [1]. PV cells converts only around $15 \%$ of the incoming solar energy into electricity and most of the rest part of the energy is converted to heat. This heat increment causes decrement of the electrical conversion

Manuscript received March. 27, 2017.

E. Kelebekler is with Kocaeli University Uzunciftlik Nuh Cimento VHS, Kartepe, Kocaeli, 41180 Turkey (e-mail: ersoy@kocaeli.edu.tr) efficiency and output power of the solar cells. An effective way of improving efficiency and reducing the rate of thermal degradation of a PV module is cooling the PV module during operation [2]. Cooling of PV cells is a critical issue in energy conversion, due to behavior of efficiency reduction with increasing temperature. Besides, excess cell temperatures will result in solar-to-electrical conversion efficiency losses and long-time high-temperature working conditions cause irreversible degradation [3].

Photovoltaic (PV) systems which convert solar energy directly into electric energy are the fastest-growing renewable energy source as quoted above. The power from the sun intercepted by the earth is about $1.8 \times 1011 \mathrm{MW}$, which is many thousands times greater than the power consumption from all sources [4]. By the end of 2014, cumulative photovoltaic capacity increased by more than 40 gigawatt $(\mathrm{GW})$ and reached at least $178 \mathrm{GW}$, sufficient to supply 1 percent of the world's total electricity consumption of currently 18,400 TWh [5]. In Europe, the capacity of photovoltaic (PV) plants has already passed 94,57 GW in 2014 [5]. On the other hand, total installed capacity of solar power in Turkey has been arrived 562.1 MW end of July in 2016 [6].

The photovoltaic effect in solids was first studied in 1876 by Adam and Day, who made a solar cell from selenium that had an efficiency of $1-2 \%$. A major improvement related to modern electronics was the discovery of a process to produce pure crystalline silicon by Polish scientist Jan Czochralski in 1916. The efficiency of first generation silicon cells was about $6 \%$, which is considerable lower than that of contemporary solar cells (about 6-20\%). Early efforts to make photovoltaic cells a viable method of electricity generation for terrestrial applications were unsuccessful due to the high device costs [7]. After seventies, usage rate started to increase and price of silicon PV cells started to decrease in parallel. The global module average selling price of crystalline silicon (c-Si) dropped from $\$ 40$ per watt in 1979 to $\$ 1.08$ per watt in 2015, while global module average selling price of cadmium telluride (CdTe) dropped from $\$ 10.3$ per watt in 1979 to $\$ 1.05$ per watt in 2014. However, initial investment cost of PV systems is still one of the biggest obstacles to become widespread. The other limiting factors which decelerate extensive use of $\mathrm{PV}$ applications include the relatively low conversion efficiency of PV cells due to heating of PV panels, dust collection on its surface, usability only at daytime and dependence on weather, requirement of additional equipment (inverters or chargers). Consequently, in order to establish PVs as a commercially 
competitive technology, it is necessary to paid high attention on the factors which affect their energy performance [8].

The electrical conversion efficiency of PV cells changes depending on its type. PV technologies can be classified in two groups silicon $(\mathrm{Si})$ based technologies and non-silicon based technologies. The silicon based technologies can also be categorized as amorphous silicon and crystalline silicon with subgroup; single/mono crystalline silicon, multi/poly crystalline silicon and ribbon cast multi-crystalline silicon. Besides, non-silicon based thin film can be also categorized cadmium telluride (CdTe) and copper indium diselenide (CIS) [7]. When the solar irradiance fall on the PV cells, the photons are absorbed by the PV cell materials and penetrate a semiconducting material and generate charge carriers. The most important of these are related to the band gap. In general the wave length of solar irradiance from $400 \mathrm{~nm}$ to $1200 \mathrm{~nm}$ are strongly absorbed by the PV cells and converted into the electric power. In a solar cell only part of the incoming irradiation is converted into electricity, as mentioned above from $400 \mathrm{~nm}$ to $1200 \mathrm{~nm}$, due to two fundamental losses that occur in a single-junction cell. Consequently, the photons having the energy inside of the band gap of PV cell materials lead to the flow of electric current from the PV cell to external load [4], [9]. Photons with energy outside of the band gap are not absorbed by the active solar cell material. These photons may reach the back surface of the solar cell, will then be reflected to a great extent and will leave the solar cell at the front side. Only a small part of the photons will be absorbed at this back surface e.g., by the metallisation, and generate heat [9].

In our study, an experimental setup in laboratory conditions is proposed and performed to work a $4.04 \mathrm{~W}$ polycrystalline silicon PV cell at fixed working temperature and under constant solar radiation simulated with 500W halogen lamp. The study organized as follows. Some cooling techniques of PV systems are mentioned in next section. In section III, the experiment setup is given. The prepared Labview software and user interface is presented with information about PI controller in section IV. Later the experimental results are given and discussed. The study is finalized with conclusion.

\section{Cooling Techniques of PV Systems}

Temperature is one of the most dominant parameter in PV systems which do affect performance of the solar cells seriously. Manufacturers generally give PV module specifications under standard test conditions (STC), i.e. 1000 $\mathrm{W} / \mathrm{m}^{2}$ irradiance, $1.5 \mathrm{AM}$ and $25{ }^{\circ} \mathrm{C}$ module temperature. However, under real operating conditions current-voltage characteristics of PV modules may change significantly according to the solar irradiance, ambient temperature, wind speed, and different mounting types [11]. Crystalline silicon (c $\mathrm{Si})$, monocrystalline silicon ( $\mathrm{mo} \mathrm{Si}$ ), and polycrystalline (p Si) $\mathrm{PV}$ modules are commonly considered the most reliable types of PV module technology. However, when the PV modules are operated in an outdoor environment, with frequent fluctuations in the environmental temperature and irradiation intensity, it gives rise to critical thermal related factors that may affect their performance and reliability of PV modules. For example, the effects of the variation of temperature and irradiation intensity inherently lead to the deterioration in the output power of PV modules. In addition, the thermal effect also influences the estimation of the maximum power point (MPP) and electrical parameters for the $\mathrm{PV}$ modules, such as maximum output power, maximum conversion efficiency, internal efficiency, reliability, and lifetime [12]. When the ambient temperature and the intensity of solar irradiance falling on the PV cells increases, the operating temperature of the PV cells also increases linearly. This increase in operating temperature of the PV cells leads to reduction in open circuit voltage, fill factor and power output for mono and poly crystalline PV cells which are used in most of the power applications. The net results lead to the loss of conversion efficiency and irreversible damage to the PV cells materials. Therefore, to overcome these effects and to maintain the operating temperature of the PV cells within the manufacturer specified value, it is necessary to remove heat from the PV cells by proper cooling methods [4]. Cooling techniques used to remove heat in order to enhance the performance of PV cells can be classified in two groups as passive cooling techniques and active cooling techniques. On the other hand, cooling techniques can be used from back side of PV modules or front side of PV modules.

The most common cooling methods are water cooling techniques, wind cooling techniques and heat pipe cooling techniques. Some of these techniques have been used only to cool PV modules or some of them have been used on hybrid photovoltaic-thermal (PV-T) systems in order to cool PV modules and collect the energy. Baloch at al. prepared water flow based PV cooling system in hot climate of Dhahran, Saudi Arabia and monitored the system performance comparatively with uncooled PV system during a year [1]. As a result of cooling system, the cell temperature was dropped from $71.2^{\circ} \mathrm{C}$ to $45.1{ }^{\circ} \mathrm{C}$ for a hot day of June and $48.3{ }^{\circ} \mathrm{C}$ to $36.4{ }^{\circ} \mathrm{C}$ for a cold weather of December. Using this active cooling technique, cell temperature was reduced by $57.8 \%$ and $32.7 \%$, respectively. Power output and conversion efficiency was improved by $35.5 \%$ and $27.5 \%$, by employing channel cooling for the data of June. Alternatively, December results revealed performance enhancement by $26.1 \%$ in power output and $36.1 \%$ in conversion efficiency. In the study [2], a laboratory-scale cooling device based on a conic wind-collecting tunnel was designed and then fabricated to cool down a photovoltaic (PV) cell. The collected wind from conic tunnel was employed with two goals; first, it was considered as a coolant fluid for PV cell. Second, it was applied for producing electrical energy via a designed turbine. The overall electric power generated from the turbine and solar cell was reported as $21 \%$ increase compared with simple cooling system. Regarding to the reference cell, the total output power was increased 36\% from both the PV cell and turbine electrical energy. A wind-driven turbine ventilator located under the PV system was used to cool PV cells in [3]. In order to supply a 
consistent rotation of the ventilator in the system, an external fan was utilized during experiments. Additionally, in order to convert the rotational motion of ventilator to electrical energy, the ventilator was equipped with a simple alternator (dynamo) with efficiency of $60 \%$. The experimental result verified that by using this setup, it is possible to reach an improvement of $46.54 \%$ in electricity production. In the study [8], water stored in isolated tank was transferred to backside of PV module through PVC (Polyvinyl Chloride) pipes by aid of a water pump $(0.5 \mathrm{hp})$. To regulate the water flow inside the cooling panel, a flow-meter with maximum flow rate of $3.6 \mathrm{~L} / \mathrm{min}$ is used. The cooling water flows through the collector, captures the waste heat from the PV module and produce hot water which is collected at the collector outlet. This active water cooling provided to drop the module temperature significantly about $20 \%$ and increase in the PV panel efficiency by $9 \%$. Interesting cooling technique was used in [13] by using aluminum fins and cotton wicks. Three aluminum fins with 2 $\mathrm{mm}$ thick were attached back side of the photovoltaic panels. A commercial grade thermal interface material was used to avoid air gap between the panel surface and fins. Flat cotton wicks 12 $\mathrm{mm}$ width and $2 \mathrm{~mm}$ thick that are commonly used for lamps and lanterns were positioned to the base of the fins with their free ends dipped in water that is stored in the headers. The maximum module temperature was reduced from 49.2 to 43.3 ${ }^{\circ} \mathrm{C}$. This corresponds to about $12 \%$ reduction in module temperature and the electrical yield was increased by $14 \%$ due to PV cooling. Another laboratory study in [14], a passive cooling system was constructed. An aluminum heat sink was used in order to dissipate waste heat from a PV cell. Dimensions of the heat sink were determined considering the results of a steady-state heat transfer analysis. Maximum power output of the PV cells both with and without fins increases with decreasing ambient temperature was presented in Tables. It is reported the PV cell with fins for the ambient temperature of 15 ${ }^{\circ} \mathrm{C}$ produces $14.4 \%$ more energy than the one without fins. Hernandez et.al. constructed an air channel backside of silicone based PV panel to improve the electrical parameters of the panel. They investigated effects of air channel spacing for different width and air flow velocity for $2 \mathrm{~m} / \mathrm{s}, 4 \mathrm{~m} / \mathrm{s}, 6 \mathrm{~m} / \mathrm{s}$ and natural convection. They reported that the electrical power of a panel cooled by forced convection is higher than that obtained by natural convection for the same aspect ratio and under the same high irradiance conditions and improvements up to $15 \%$ in electrical power and decrease of panel temperature of about $15{ }^{\circ} \mathrm{C}[15]$.

\section{EXPERIMENT SETUP}

Air as a cooling tool for PV module or heat collector has been used and investigated in many studies [2],[3], [14],[15]. In laboratory conditions, a conic wind-collecting tunnel and a wind-driven turbine ventilator was used to collect and drive air to PV module for active cooling in [2] and [3], respectively. In the study [14], performance of passive air cooling method using aluminum heat sink as dissipater waste head was investigated in laboratory conditions. Cooling performance of an air channel backside of silicone based PV panel depending on air flow velocity for $2 \mathrm{~m} / \mathrm{s}, 4 \mathrm{~m} / \mathrm{s}, 6 \mathrm{~m} / \mathrm{s}$ and natural convection was studied in [15] and it was reported that the air cooling system supplies the electrical power up until \%15. In our study, it is purposed to show cooling capability of active air cooling system consisting PV cell, temperature sensors and air ventilators in laboratory conditions. Besides it is investigated possibility of working PV cell at fix temperature by the help of air blowing.

The experiment structure consists of a $4.04 \mathrm{~W}$ polycrystalline silicon solar cell, two LM 35 temperature sensors, a 500W halogen lamp as a solar simulator, an ACS 714 current sensor, two ventilators, two BD 139 transistors to drive the motors of ventilators and NI 6002 Data Acquisition Card. The temperature sensors have been glued backside of the PV cell by the aid of silicon gun as in Figure 1. Silicon heat transfer compound has been applied between PV module backside and temperature sensors in order to enhance heat transfer. Additionally backside of the temperature sensors covered with silicon to cut heat transfer between the sensors and air.

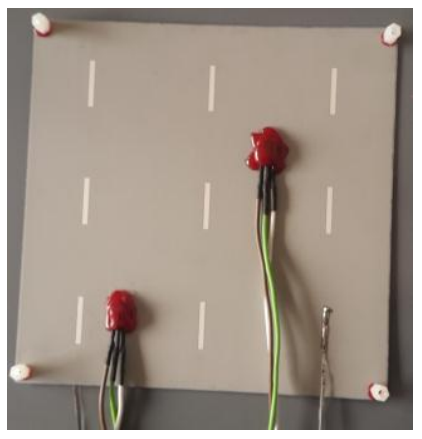

Figure 1. Location of temperature sensors

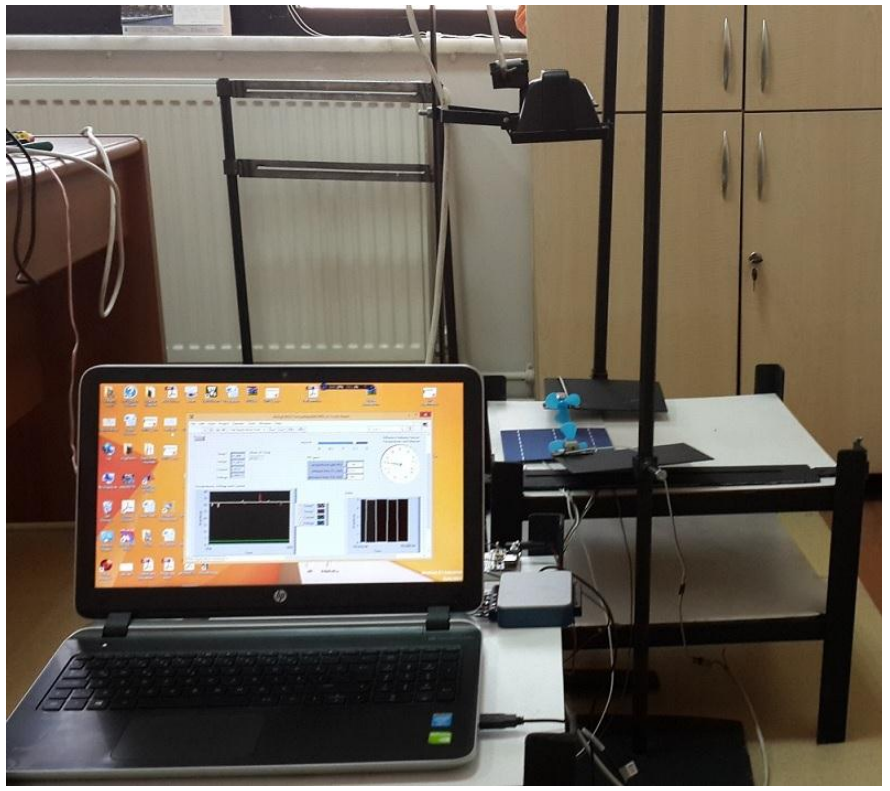

Figure 2. Experiment Setup

The experiment setup constructed to measure PV cell working temperature and supply to work PV cell at fixed 
working temperature is given in Figure 2, while the solar radiation is constant.

The solar simulator, a halogen lamp, was placed $450 \mathrm{~mm}$ up from the PV cell for all experiment processes. Two ventilators, which have $12 \mathrm{~V}$ DC, $16000 \mathrm{rpm}$ with no load, were located both side of PV cell as given in Figure 3. When the solar simulator was manipulated, the working temperature of the cell taken two points at backside of the PV cell, the voltage and the current obtained from the PV cell for $0,47 \Omega$ load resistance were taken by aid of NI 6002 data acquisition card and recorded by aid of prepared Labview software. The PV cell was cooled with two ventilators driven via BD 139, medium power linear and switching transistor, by using PWM signal. Speed of the ventilators was controlled by chancing duty cycle of PWM signal by aid of PI controller in Labview software.

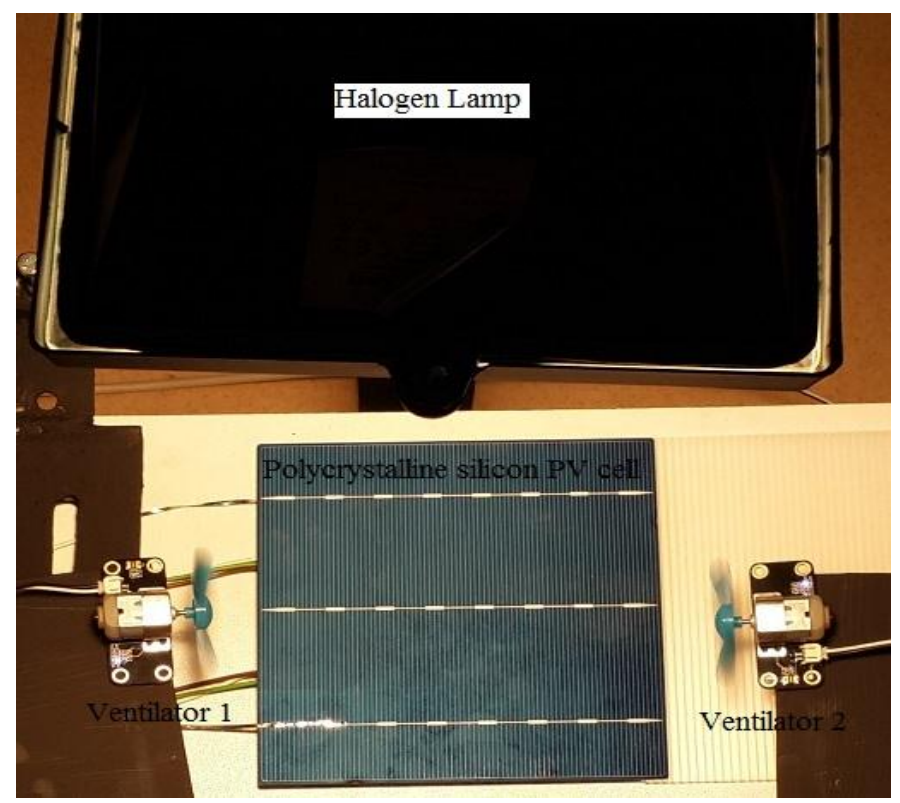

Figure 3. Simulated PV cell and location of the ventilators

\section{LABVIEW SOFTWARE AND PI CONTROLLER}

The software prepared in Labview 2012 and the user interface of it given in Figure 4 and Figure 5, respectively.

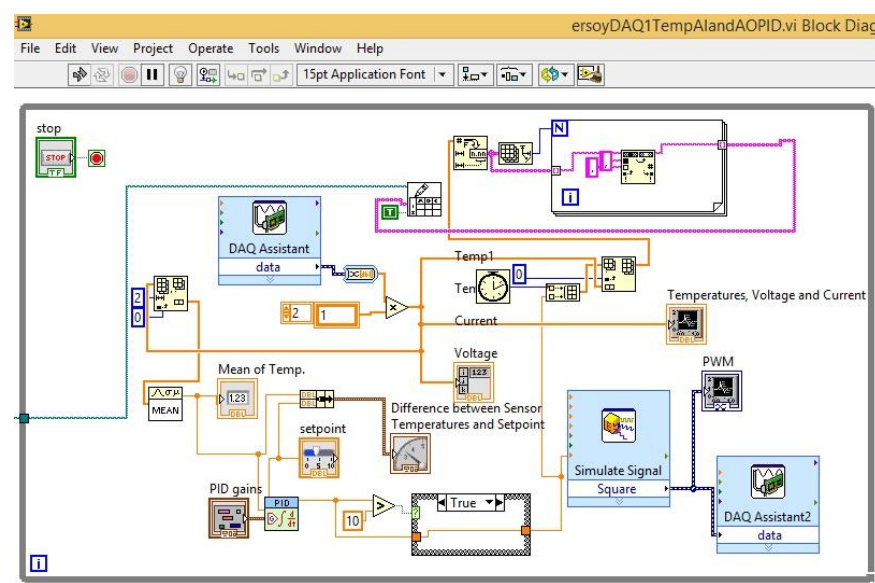

Figure 4. The prepared software in Labview
Two DAQ Assistant tools were used in the software. One of them located upper left in Figure 4 takes the analog data; temperatures, voltage and current. The other located lower right corner is used to drive ventilator with produced PWM signal by simulate signal tool. Duty cycle of PWM signal is limited not reduce $10 \%$ of the signal because the ventilator motors cannot move under this duty cycle value.

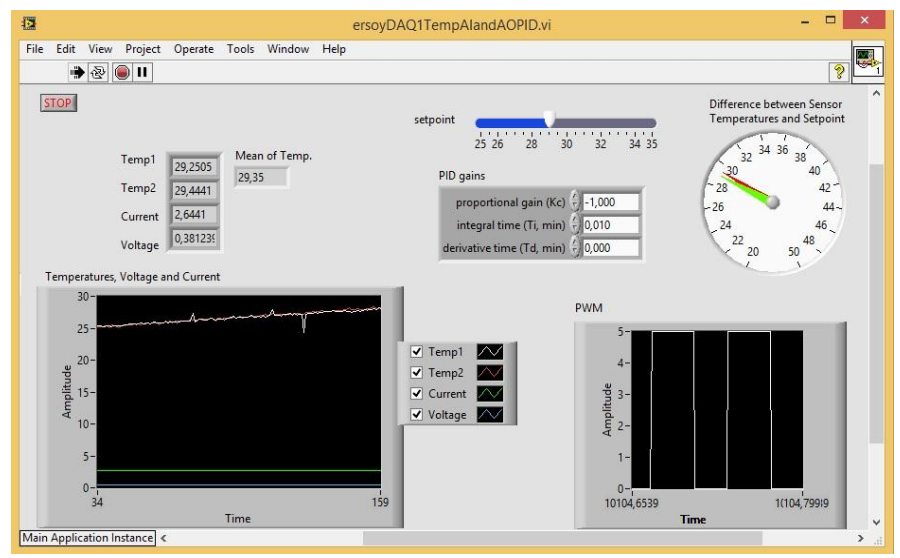

Figure 5. The user interface of the software

The user interface was prepared to adjust the set point of the working temperature of the cell, gains of the PID controller and watch instantaneous values of temperature, current, voltage and mean of temperatures and difference between mean of temperatures and setpoint as shown in Figure 5. Additionally these variables and PWM signal can be watched at chart graphs.

The $\mathrm{P}$ controller is mainly used to reduce the steady state error of the system. $\mathrm{K}_{\mathrm{p}}$ is the proportional gain factor decreases the steady state error while increasing. Additionally increasing $\mathrm{K}_{\mathrm{p}}$ supplies larger sensitivity, faster dynamic satisfying wider frequency and smaller amplitude. The steady state error resulting from $\mathrm{P}$ controller can be eliminate by using PI controller. Nevertheless it has negative impact on overall stability of the system and speed of response. When the speed of the system is not important, the PI controller is used. The PI controller cannot reduce the rise time and remove the oscillations. The PD controller increases the stability of the system by improving control since it has an ability to predict the future error of the system response. In order to avoid effects of the sudden change in the value of the error signal, the derivative is taken from the output response of the system variable instead of the error signal. Besides D control is not used alone in the system because of amplifying process noise. PID control has the optimum solutions for the systems including zero steady state error, shorter rise time, higher stability and no oscillations. The effects of increasing PID controller parameters are resumed in Table [16]. 
TABLE 1. EFFECTS OF INCREASING THE PID CONTROLLER PAREMETERS

\begin{tabular}{lllll}
\hline \hline Parameter & $\begin{array}{l}\text { Steady State } \\
\text { Error }\end{array}$ & Rise Time & Settling Time & Overshoot \\
\hline $\mathrm{K}_{\mathrm{p}}$ & Decrease & Decrease & Small Change & Increase \\
$\mathrm{K}_{\mathrm{I}}$ & Reduce & Decrease & Increase & Increase \\
$\mathrm{K}_{\mathrm{D}}$ & Small Change & Small Change & Decrease & Decrease \\
\hline \hline
\end{tabular}

In our system, the temperature values obtained from temperature sensors are used to control speed of ventilators which blow directly monocrystalline silicon PV cell to cool. The temperature value of the PV cell changes almost slowly depending on difference solar simulator from PV cell. The PI controller is used in the system because the PI control can be preferred when the speed of the system is not important as mentioned above. $\mathrm{K}_{\mathrm{p}}$, the proportional gain factor and $\mathrm{K}_{\mathrm{I}}$, the integration factor are taken -1 and 0,01 , respectively.

\section{EXPERIMENTAL MEASUREMENTS AND RESUlTS}

The main purpose of our study to supply PV cell to worked at fixed working temperature while solar radiation is not changing. In the study, firstly, it was determined how much the system heats without air blow cooling. The experiments were performed in laboratory conditions at $23{ }^{\circ} \mathrm{C}$. The experimental results of uncooling system for mean working temperature, current and voltage is given in Figure 6 . The mean temperature taken two temperature sensors arrives $23{ }^{\circ} \mathrm{C}$ to $49{ }^{\circ} \mathrm{C}$ end of nine minutes. While the current almost never changes, the output voltage or load voltage drops from $0,44 \mathrm{~V}$ to $0,39 \mathrm{~V}$ in nine minutes. This characteristic was reported in many studies as presented in section I and section II.
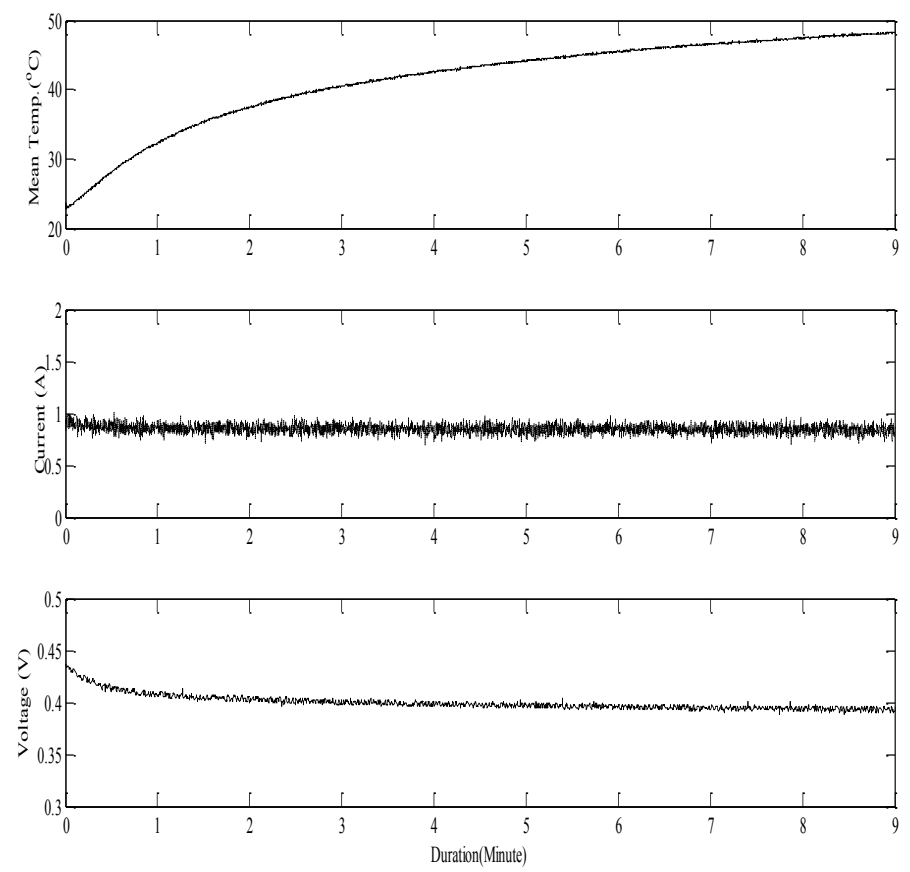

Figure 6. Mean temperature, current and voltage values without cooling

In laboratory conditions, the halogen lamps are commonly used to simulate solar radiation. This simulation causes to swiftly raise medium temperature and decrease output voltage and PV efficiency. In order to resolve this unstable medium and work PV cell at fixed working temperature, primarily, cooling capability of direct air blow to PV cell with two ventilators was investigated. The mean working temperature, current and voltage for full capacity of ventilators is taken during nine minutes and given in Figure 7.

The cooling with prepared structure for full capacity of ventilators provides to stay mean working temperature under $29^{\circ} \mathrm{C}$. Beside the output current and voltage can stay rather stable at this temperature range as seen in Figure 7. The results about capability of the cooling system show us impossible to work the system at fixed working temperature under $29{ }^{\circ} \mathrm{C}$ because the prepared system cannot cool more. Additionally, it must be reminded that the cooling performance of direct air blow system is depended on medium temperature conditions. If the laboratory temperature conditions are changed, the system can provide lower or higher minimum working temperature.
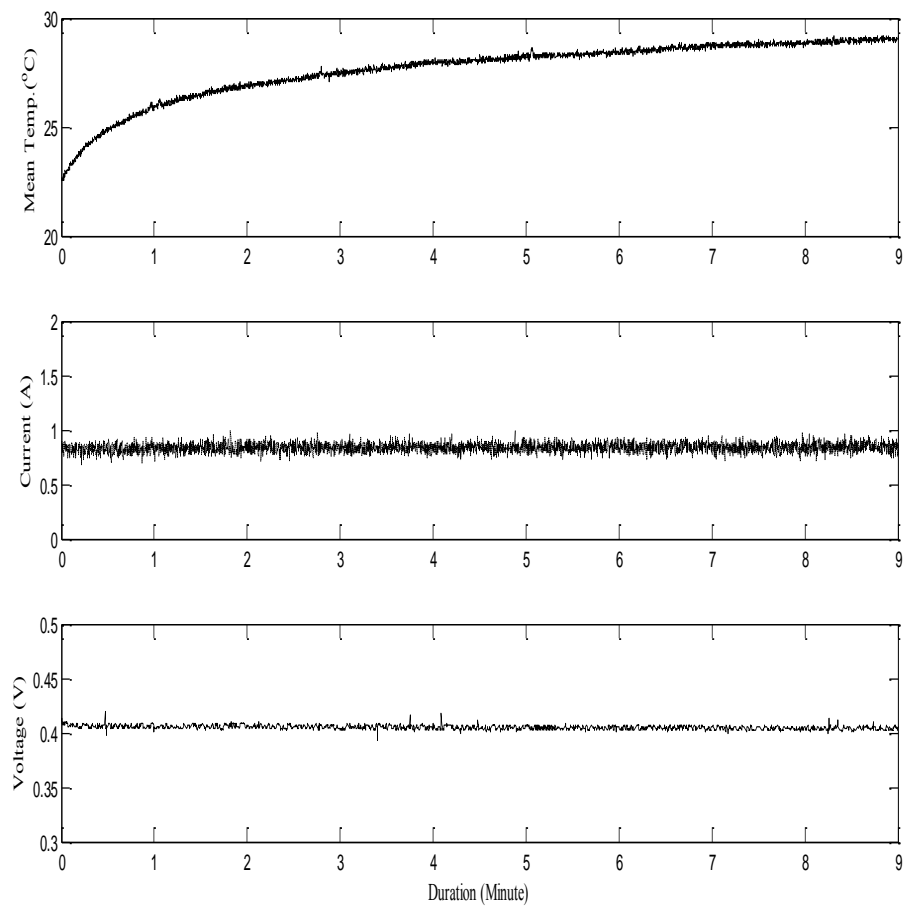

Figure 7. Mean temperature, current and voltage values with fixed cooling

The prepared air blow cooling system is aimed PV cell to work at fixed working temperature. In order to provide fixed working temperature, speed of the ventilators is controlled by help of PI controller created in Labview 2012 as given in Figure 4. The PI controller arranges the PWM duty cycle, thereby speed of ventilators, depending on mean working temperature. The setpoint determines preferred working temperature of PV cell by using user interface in Figure 5. As mention previous section, in experimental process, the proportional gain factor, $\mathrm{K}_{\mathrm{p}}$, and the integration factor, $\mathrm{K}_{\mathrm{I}}$, are taken -1 and 0,01 , respectively. The mean working temperature values and duty cycle values of PWM signal for different set points is given in Figure 8. 
The horizontal axis shows experiment duration in minute while the left vertical axis and right vertical axis show mean working temperature of polycrystalline silicon PV cell and duty cycle of PWM signal, respectively.
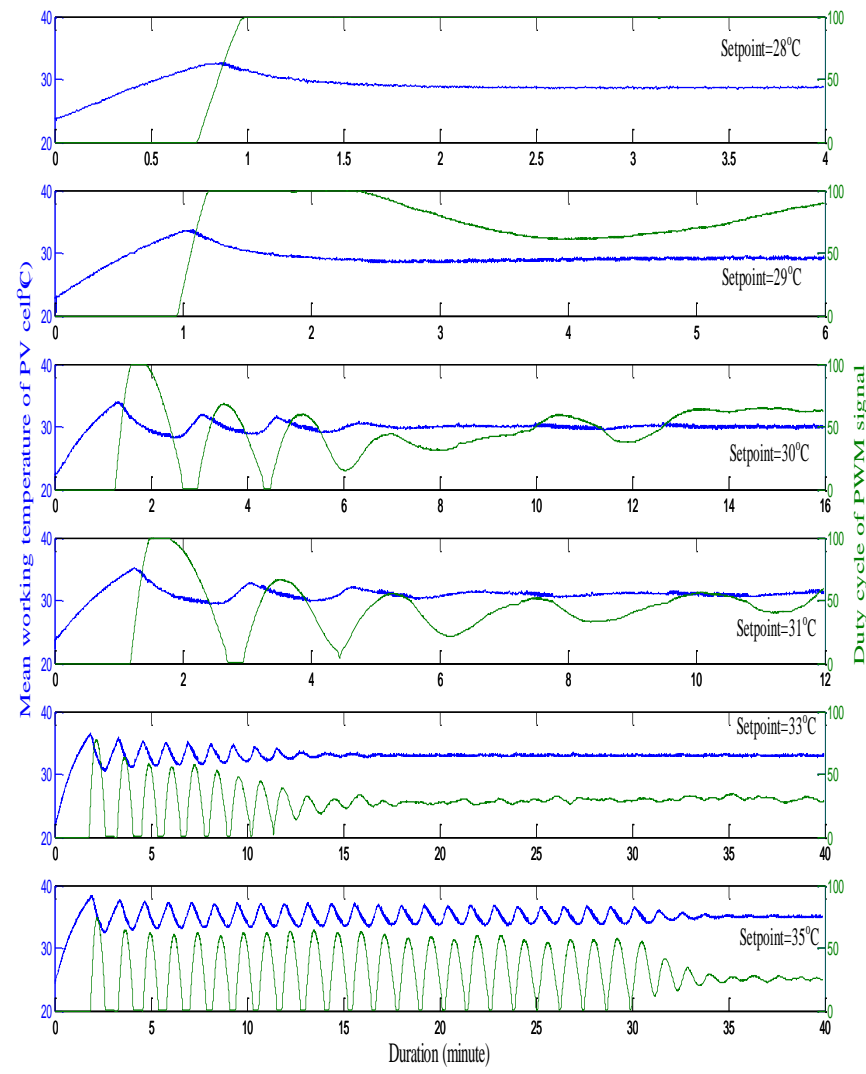

Figure 8. Duty cycle value of PWM signal depending on mean working temperature of PV cell for different setpoint values

The first subplot is given for setpoint $28{ }^{\circ} \mathrm{C}$. The mean working temperature starts from laboratory conditions and arrives above $30{ }^{\circ} \mathrm{C}$. The ventilators start to turn with increasing duty cycle after the setpoint value is exceeded. The duty cycle arrive $100 \%$ and stay this value because the maximum performance of ventilators cannot cool enough the system. In the second subplot, the set point is arranged as $29^{\circ} \mathrm{C}$. After the mean working temperature of PV cell exceed the setpoint, the duty cycle increase fast and arrive $100 \%$, full performance of cooling system. The ventilators works with maximum rpm until the mean temperature drops to the setpoint. As can be seen in second subplot, the duty cycle of PWM signal increases slowly after fourth minute because the halogen lamp heats the experiment medium in the laboratory. Therefore it is needed to blow to the cell much more.

The third subplot shows the results for setpoint $30^{\circ} \mathrm{C}$. After the mean working temperature exceeds the setpoint, the duty cycle increases fast. But this cause to drop the temperature much more than setpoint. Therefore duty cycle drops and ventilators speed decreases again. The PI controller arranges duty cycle a few times and speed of ventilators to cool or enable to heat the cell. Similar behavior is monitored in last three subplots. The setting time for last for subplots is much more the second setpoint $29^{\circ} \mathrm{C}$. Additionally the setting time increases while the setpoint for working temperature of PV cell increases as seen in Figure 8. This shows us that it is necessary to study on PI parameters for better setting time and control system. The duty cycle of PWM signal increases slowly after the system is set because the halogen lamp heats the experiment medium in the laboratory as mentioned above. As a consequence, it is necessary to blow to the cell much more in order to hold stable the working temperature.

\section{CONCLUSION}

An experimental setup in laboratory conditions is proposed and performed to work polycrystalline silicon PV cell at fixed working temperature under constant solar radiation. The experiment setup consists of a $4.04 \mathrm{~W}$ polycrystalline silicon solar cell, two temperature sensors to measure working temperature, a $500 \mathrm{~W}$ halogen lamp to simulate the cell, a current sensor, two ventilators to blow air for cooling the cell and NI 6002 Data Acquisition Card to take and record experimental results. The halogen lamp was located $450 \mathrm{~mm}$ up from the PV cell for constant radiation during all experiments. In order to provide fixed working temperature of PV cell, speed of the ventilators was controlled by chancing duty cycle of PWM signal by aid of PI controller in Labview software. Besides a user interface was prepared to adjust the set point of the working temperature of the cell, gains of the PID controller and watch instantaneous values of temperature, current, voltage and mean of temperatures and difference between mean of temperatures and setpoint. The PI controller is used in the system because the PI control can be preferred when the speed of the system is not important. In all experiments, $K_{p}$, the proportional gain factor and $\mathrm{K}_{\mathrm{I}}$, the integration factor are taken -1 and 0,01 , respectively.

In the study, firstly, it was determined how much the system heats without air blow cooling and cooling capability of the prepared system with two ventilators. Working full capacity of ventilators provides to stay mean working temperature under $29^{\circ} \mathrm{C}$. The mean working temperature of PV cell and duty cycle of PWM signal depending on experiment duration is given for different setpoint values, $28^{\circ} \mathrm{C}, 29^{\circ} \mathrm{C}, 30^{\circ} \mathrm{C}, 31^{\circ} \mathrm{C}, 33^{\circ} \mathrm{C}$ and $35^{\circ} \mathrm{C}$. The results show affectivity of the prepared system. Nevertheless it is observed that the setting time increases and occurs fluctuations much more until setting the system while the setpoint increases. In order to obtain better PI parameters for better setting time and control system, a study can be performed as a future study.

\section{REFERENCES}

[1] A.A.B. Baloch, H.M.S. Bahaidarah, P. Gandhidasan, F.A. Al-Sulaiman, "Experimental and numerical performance analysis of a converging channel heat exchanger for PV cooling," Energy Convers Manag., vol 103, pp. 14-27, 2015. 
[2] M. Rahimi, P. Valeh-E-Sheyda, M.A. Parsamoghadam, M.M. Masahi, A. A. Alsairafi, "Design of a self-adjusted jet impingement system for cooling of photovoltaic cells," Energy Convers Manage, vol 83, pp. 48-57, 2014.

[3] P.V. Sheyda, M. Rahimi, A. Parsamoghadam, M. M. Masahi, "Using a wind-driven ventilator to enhance a photovoltaic cell power generation," Energy Build, vol. 73, pp.115-119, 2014.

[4] S. Sargunanathana, A. Elangob, S. Tharves Mohideenc, "Performance enhancement of solar photovoltaic cells using effective cooling methods: A review," Renewable and Sustainable Energy Reviews, vol. 64, pp. 382-393, 2016

[5] https://en.wikipedia.org/wiki/Solar_power_by_country

[6] http://solar.ist/turkiye-gunes-enerjisinde-5621-mwa-ulasti/

[7] R. Kumar, M.A. Rosen, "A critical review of photovoltaic-thermal solar collectors for air heating," Appl Energy, vol. 88, no. 11, pp. 3603-3614, 2011.

[8] H. Bahaidarah, A. Subhan, P. Gandhidasan, S. Rehman, "Performance evaluation of a PV(photovoltaic) modüle by back surface water cooling for hot climatic conditions," Energy, vol. 59, pp. 445-453, 2013.

[9] W. G. J. Van Helden, R. J. C. Van Zolingen, H. A. Zondag, "PV thermal systems: PV panels supplying renewable electricity and heat," Progress in Photovoltaics: Research and Applications, vol. 12, pp. 415-426, 2004.

[10] E. Skoplaki, J. A. Palyvos, "On the temperature dependence of photovoltaic module electrical performance: a review of efficiency/power correlations," Solar Energy, vol. 83, pp. 614-624, 2009.

[11] N. Gökmen, W. Hu, P. Hou, Z. Chen, D. Sera, S. Spataru, "Investigation of wind speed cooling effect on PV panels in windy locations," Renewable Energy, vol. 90, pp. 283-290, 2016.

[12] J.A. Jiang, J.C. Wang, K. C. Kuo, Y. L. Su, J. C. Shieh, J.J. Chou, "Analysis of the junction temperature and thermal characteristics of photovoltaic modules under various operation conditions," Energy, vol. 44, no. 1, pp. 292-301, 2012.
[13] M. Chandrasekar, and T. Senthilkumar, "Passive thermal regulation of flat PV modules by coupling the mechanisms of evaporative and fin cooling," Heat Mass Transfer, vol. 52, pp. 1381, 2016.

[14] E. Cuce, T. Bali, S.A. Sekucoglu, "Effects of passive cooling on performance of silicon photovoltaic cells," International Journal of Low-Carbon Technologies, vol. 6, no. 4, pp. 299-308, 2011.

[15] R. Mazón-Hernández, J. R. García-Cascales, F. Vera-García, A. S. Káiser, and B. Zamora, "Improving the Electrical Parameters of a Photovoltaic Panel by Means of an Induced or Forced Air Stream," International Journal of Photoenergy, pp. 1-10, 2013.

[16] S. K. Suman, V. K. Giri, "Speed control of DC motor using optimization techniques based PID controller," 2nd IEEE International Conference on Engineering and Technology (ICTECH 2016), India, March 17-18, 2016.

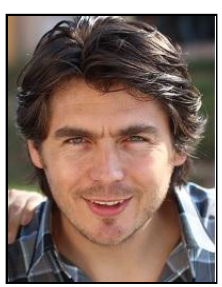

Ersoy Kelebekler was born in Bursa, Turkey in 1980. He received the B.S. and M.S. degrees in department of electronics and computer education from Kocaeli university, in 2002 and 2006, respectively. He is completed the Ph.D. study on investigation of propagation constant of gyroelectric medium loaded closed waveguides at Kocaeli University, in 2012.

$\mathrm{He}$ was worked as a research assistant at the department of electronics and computer education of Kocaeli university between 2002 and 2004. He is currently working as an Assistant Professor at Alternative Energy Sources Department of Uzunciftlik Nuh Cimento VHS of Kocaeli University. His research interests are in renewable energy sources, computer-aided analysis of active and passive circuits and theoretical electromagnetics. 